\title{
Kemik metastazlarında sistemik tedaviler
}

\author{
Systemic treatment options for bone metastases
}

\author{
Ulus Ali Şanlı, Murat Karateke, Elvina Almuradova \\ Ege Üniversitesi Tıp Fakültesi, Tıbbi Onkoloji Bilim Dalı, İzmir
}

\begin{abstract}
Kanser hastalarında ölümün en önemli nedeni uzak metastazlardır. Karaciğer ve akciğerden sonra üçüncü en sık uzak metastaz yeri kemiktir. Kanser tedavisinde yeni tedavi seçenekleri, metastatik kanserli hastaların sağkalım oranlarını artırmıştır. Bunun sonucu olarak, kemik metastazlarına bağlı morbidite oranları da artış göstermektedir. Patolojik kırıklar ve spinal felç gibi iskeletle ilgili olaylar, günlük aktivitelerde ve yaşam kalitesinde bozulmaya neden olur. Ciddi iskelet ilişkili olaylardan kaçınmak için erken tanı ve profilaktik tedaviler gereklidir. Bu yazıda kemik metastazı için sistemik tedavi seçenekleri tartışılacaktır.
\end{abstract}

Anahtar sözcükler: kemik tümörleri; tümör metastazı; sistemik tedavi

K anser hastalarında ölümün en önemli nedeni uzak metastazlardır. Karaciğer ve akciğerden sonra üçüncü en sık uzak metastaz yeri kemiktir. ${ }^{[1]}$ Kemik metastazları kanserde sık görülen komplikasyonlardandır. Bunların yaklaşı \%80'ini ileri evredeki meme, prostat ve akciğer kanserli olgular oluşturur. Kanser tedavisindeki gelişmeler sayesinde hastaların sağkalım süreleri artmakta ve dolayısıyla kansere bağIı kemik metastazları sıklığı da artış göstermektedir. Kemik metastazlarına bağlı olarak gelişen iskelet ilişkili olaylar (skeletal-related events -SRE'ler) kemik metastazı ilişkili olumsuz olayları tanımlamak için kullanılan bir terimdir; patolojik kırık, metastaza bağlı cerrahi veya ışın tedavisi gereksinimi, omurilik sıkışması ve malign hiperkalsemiyi içerir. ${ }^{[2]}$ Kemik metastazlarına bağlı SRE olması ölüm oranını \%20'den \%40'a çıkaran en önemli kötü prognostik faktörlerden birisidir. ${ }^{[3]}$ illk SRE atağından sonra ikincinin gelişmesi daha hızlı olabilmektedir. Yapılan birçok çalışmada kemik metastazına
The most important cause of mortality in cancer patients is distant metastases. The third most common distant metastasis after liver and lung is bone. New inventions in cancer treatment has improved the survival of patients with metastatic cancers. As a result, clinical courses of patients are prolonged, and followed by morbidity due to bone metastases. Skeletal-related events, such as pathological fractures and spinal paralysis, cause impairment in activities of daily life, and quality of life. To avoid serious skeleton related events, early diagnosis and a prophylactic treatment are required. In this article, systemic treatment options for bone metastases will be discussed.

Key words: bone neoplasms; neoplasm metastasis; systemic treatment bağlı olayların gelişmesinin yaşam süresini yarı yarıya indirdiği görülmüştür. ${ }^{[4,5]}$ Yine bazı kaynaklarda SRE gelişen hastalarda medyan sağkalımın dört ay olduğu bildirilmektedir. ${ }^{[6]} \mathrm{Bu}$ nedenle kemik metastazlarının tedavi edilmesi onkolojinin en önemli sorunlarından biridir. Meme, akciğer, prostat, tiroid kanseri gibi hastalıklarda uzak metastazların \%60'tan fazlasını kemik metastazı oluşturmaktadır. ${ }^{[7]}$

Kemik metastazlarında kemik yıkımı lehine denge bozulur ise osteolitik lezyonlar, kemik yapımı lehine denge bozulur ise osteoblastik lezyonlar görülür. Bazen de miks tip metastatik lezyonlar görülür. Kemik metastazları kanser tipine göre farklılık gösterir. Meme ve akciğer kanserinde osteolitik, prostat kanserinde daha çok osteoblastik metastaz görülse de bunlar miks tipte de olabilir. ${ }^{[8-13]}$

Kemik metastazı olan hastalar hiç bir belirti olmadan, rastlantısal olarak saptanabildiği gibi

- Illetişim adresi: Prof. Dr. Ulus Ali Şanlı, Ege Üniversitesi Tıp Fakültesi, Tülay Aktaş Onkoloji Hastanesi, Bornova, İzmir Tel: 0232 - 3904607 e-posta: ulus.ali.sanli@ege.edu.tr

- Geliș tarihi: 1 Ekim 2019 Kabul tarihi: 6 Kasım 2019 
hiperkalsemi veya sinir basısına bağlı olarak nörolojik patoloji kliniğiyle de karşımıza gelebilir. Spinal kord basısı ve hiperkalsemi acil tedavi edilmesi gereken durumlardır. ${ }^{[14-16]}$ Alt ekstermitede hissizlik, yürüme zorluğu, kauda ekina, bel ağrısı gibi şikâyetler spinal kord basısına, anoreksi, bulantı, kusma, poliüri, hiporefleksi, tremor ve konfüzyon ise malign hiperkalsemiye işaret eden belirtiler olabilir. ${ }^{[17]}$

Kemik metastazlarının saptanması için çeşitli görüntüleme yöntemleri mevcuttur. Kemik sintigrafisi (KS), 18F-fluorodeglukoz pozitron emisyon tomografisi (PET) ve manyetik rezonans (MR) görüntüleme bu amaçla en sık kullanılan görüntüleme yöntemleridir. Kemikteki metastazların saptanmasında kemik sintigrafisi duyarlılığı \%86, özgüllügüü \%81, $\mathrm{PET/BT} \mathrm{(pozit-}$ ron emisyon tomografisi / bilgisayarlı tomografi) için uygun olarak $\% 90$ ve $\% 97$, MR için ise bu $\% 91$ ve $\% 95$ olduğu bilinmektedir. ${ }^{[18-21]}$ Kemoterapi, hedef tedaviler ve hormonal tedavi tümör boyutunu küçülterek ve ağrı sinyallerini engelleyerek ağrı azaltmada etkili olabilir.

Prostat kanserinde kastrasyon dirençli, semptomatik metastatik olgularda docetaksel kemoterapisinin hastalık tedavisinde ve tümör ilişkili kemik ağrılarının azaltılmasında önemli rolü vardır. ${ }^{[22]}$

Standart hormon tedavisinin amacı ise testosteron düzeyini medikal veya cerrahi olarak kastrasyon seviyelerinde tutmak ve metastatik odakların kontrolünü sağlayarak hastanın yaşam kalitesinde iyileşme sağlamaktır. Nüks eden ya da tanı anında metastatik olan hastalarda ADT (androjen deprivasyon tedavisi) standart tedavi yaklaşımıdır. Günlük onkoloji pratiğinde sık kullanılan ADT modaliteleri ise, cerrahi kastrasyon (orşiektomi), Gn-RH reseptör agonistleri ve antagonistleri ve anti androjenler, olarak sıralanabilir. On randomize kontrollü çalışmada, 1908 ileri evre prostat kanseri hastası ile yapılan meta-analizde LH-RH agonistleri (leuprolid, goserelin) arasında etkinlik ve genel sağkalım (OS) farkı saptanmamıştır. ${ }^{[23]}$

Androjen sentez inhibitörü olan abirateron ve androjen reseptör antagonisti olan enzalutamid ise farklı mekanizmalar ile apopitozisi indüklerken, kanser hücresinde büyüme ve gelişimi inhibe eder. Kastrasyon rezistans prostat kanserli hastaların tedavisinde abirateron ile enzalutamid karşılaştırması yapılan hiçbir Faz III denemesi yoktur ve bir ajanın diğerine göre seçilmesi toksisite profillerine ve hastaya özgü faktörlere dayanmaktadır.

ENZAMET (ANZUP 1304) çalışmasında 1125 metastatik hormon sensitif prostat kanserinde ADT ile $160 \mathrm{mg} /$ gün enzalutamid ve standart nonsteroidal antiandrojenleri kıyaslanmış olup enzalutamid belirgin genel sağkalım farkı sağlamıştır (\%72'ye karşı \%80).
Enzalutamid kolunda biyokimyasal ve klinik progresyon da daha geç görülmüştür. Ancak enzalutamid kolunda 7 (\%1) hastada nöbet gelişmiştir. ${ }^{[24]} \mathrm{Faz}$ III ARCHES çalışmasında 1150 metastatik hormona duyarlı prostat kanseri hastasında enzalutamid + ADT kolunda 14,34 aylık medyan izlemde radyografik hastalıksız sağkalımda belirgin iyileşme görülmüştür (HR 0,39, \%95 Cl 0,30-0,50). ${ }^{[25]}$

Apalutamid, enzalutamidle benzer mekanizmaya sahip olan ancak santral sinir sistemi toksisitesi daha az görülen ajandır. TITAN çalışmasında 1052 hastada ADT + apalutamid ve plasebo koluna ayrıldı. Yüzde 11 hasta daha önceden docetaxel kemoterapisi almıştı. Yirmi üç aylık medyan izlemde genel sağkalım ADT + apalutamid kolunda belirgin artmış olarak görüldü (iki yıllık genel sağkalım \%82'ye karşın \%74). ${ }^{[26]}$

LATTITUDE çalışmasında kastrasyon sensitif metastatik prostat kanseri olup, en az iki yüksek risk faktörü (Gleason skoru 8'den büyük en az üç kemik lezyonu, visseral metastaz) olan hastalarda medyan sağkalım 53,3 'e karşı 36,5 ay (HR 0,66, \%95 Cl 0,56-0,78) olduğu görüldü. ${ }^{[27]}$ Abirateronun steroidle kombine şekilde kullanılması nedeniyle görülen en önemli yan etkiler bu nedenli idi.

Yüksek riskli (T3-T4 N0 M0, PSA >40ng/mL, Glisson 8-10 veya nod pozitif veya metastatik) prostat kanseri hastalarında abirateron etkinliğini araştıran diğer çalışma STAMPEDE'dir. Genel sağkalım \%83'e karşı \%76 oranla abirateron kolunda üstün çıkmıştır (HR 0,63,

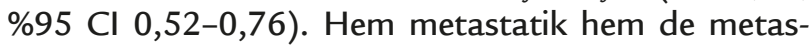
tatik olmayan hasta grubunda etkinlik benzer olarak görülmüştür (HR 0,75 ve 0,61). ${ }^{[28,29]}$

Daha önce tedavi almamış, kastrasyon duyarlı ve kemik metastazları olan prostat kanserinde ADT ile ADT + dosetaksel tedavisini karşılaştıran CHAARTED çalışmasında 29 aylık izlemde kemoterapi + ADT kolu biyokimyasal, semptomatik, radyolojik olarak üstün olduğu görülmüştür. (20’ye karşı 12 ay, HR 0,61, \%95 CI 0,52-0,72). ${ }^{[30]}$ Yine STAMPEDE çalışmasında ADT tedavisine dosetaksel eklenmesi tek başına ADT tedavisine kıyasla belirgin genel sağkalım avantajı sağlamıştır (medyan 81 aya karşı 71 ay). ${ }^{[31]}$

Meme kanserinin tedavisinde östrojen etkilerini ortadan kaldıran hormonoterapi ajanları, hormon reseptör pozitif alt grupta hem adjuvan hem de metastatik hatta en sık kullanılan ajanlar arasındadır. Oligometastatik hastalıkta özellikle sadece kemiklerde metastazı olup, hastalık yükü az olan hastalarda ilk ve hatta yanıt durumuna göre ikinci tedavi seçeneği hormonoterapidir. Meme kanserinde kemik metastazlarının hormona hassas olduğu uzun yıllardan beri bilinen bir durumdur ve bu nedenle hastalar hormonoterapi 
(anti-östrojenler) ve antirezorptif ajanların kombinasyonundan yarar görmektedir. Anti-östrojen tedaviler olan tamoksifen, aromataz inhibitörleri, fulvestrant ve onların CDK 4/6 inhibitörleriyle kombinasyonuyla belirgin tedavi yanıtları elde edilmektedir. ${ }^{[32]}$ Hastalık yükü fazla olan, visseral metastazı olan hastalarda sadece anti-östrojen tedavisi yeterli olmayacağından bu hastalarda kemoterapi, hastalık tedavisi için gerekse de, hastaların genel durumu ve şiddetli ağrısı nedeniyle kemoterapiyi tolere etmesi zor olabilir. Bu nedenle, bu gibi durumlarda öncelikle lokal tedaviler uygulanıp sonrasında sistemik tedavi uygulanması daha iyi sonuçlar gösteriyor.

İzole kemik metastazları olan hastalarda hormon reseptörü pozitif durumda seçilecek en iyi tedavi yöntemi hormonoterapidir. Hangi ilaç ve ya kombinasyonun seçilmesi ise pre- ve post-menopoz durumuna göre belirlenir.

Metastatik hormon pozitif post-menopozal hastalar için adjuvan endokrin tedavi sonrası ilk sıra tedavi aromataz inhibitörü ile CDK 4/6 inhibitörü (palbosiklib, ribosiklib, abemasiklib) kombinasyon tedavisi veya alternatif olarak bir steroidal anti-östrojen olan fulvestrant ve CDK4/ 6 inhibitörü kombinasyon tedavisi verilebilir. ${ }^{[32-34]}$ CDK 4/ 6 inhibitörlerini baş başa karşılaştıran çalışma mevcut değildir, bu nedenle ilaç seçimi yan etki profiline göre hasta bazında yapılabilir. Hastalık yükü az olan hastalarda tek başına aromataz inhibitörü kullanımı da mümkündür. Adjuvan tedavide aromataz inhibitörü kullanan veya ilk hat endokrin tedavi sonrası progresyon gelişen, visseral krizi olmayan hastalarda fulvestrant yine etkin tedavi seçeneğidir. Agonistik etkileri olmaması nedeniyle fulvestranta direnç gelişimi de çok az görülmektedir. ${ }^{[35-38]}$ Fulvestrantın CDK4/6 inhibitörleriyle kombinasyonunun etkinliğini gösteren MONALEESA, PALOMA, MONARCH çalışmalarında kombinasyon tedaviyle belirgin progresyonsuz sağkalım avantajı sağladığı görüldükten sonra, bu tedavi şekli de FDA tarafından onaylanmıştır. ${ }^{[39]}$

Endokrin tedaviye direnç gelişiminde önemli faktörlerden biri de PIK3CA mutasyonunun olmasıdır. Bu mutasyonu taşıyan ve endokrin tedaviye direnç gelişmiş olgularda Fulvestrant ile birlikte PIK3 inhibitörü ALPESILIB kullanımı da onay almış tedavidir (11,0'e karşı 5,7 ay HR 0,65, \%95 Cl 0,50-0,85).. ${ }^{[40]}$ Ayrıca Everolimus ( $m$-TOR inhibitörü) + eksemestan tedavisi de yine ikinci hat tedavide özellikle bu yol üzerinden etki ederek belirgin yanıt oranlarına sahiptir. ${ }^{[41]}$

SWOG S0226 çalışmasında, 707 metastatik hormon pozitif hastada fulvestrant + Ai ile Ai karşılaştıııldı. Progresyonsuz sağkalım (15 aya karşı 14 ay; HR 0,81, $\% 95 \mathrm{Cl} 0,69-0,94)$ ve genel sağkalım ( 50 aya 42 ay; HR 0,82, \%95 Cl 0,69-0,98) istatiksel ve klinik olarak anlamlı saptandığı için diğer ajanlara ulaşılmadığında bu tedavi kombinasyonu da iyi bir seçenektir. ${ }^{[42]}$

Pre-menopozal hastalarda da genelde benzer tedavi seçenekleri olmakla birlikte bu kadınlarda fonksiyonel overlerin olması nedeniyle medikal ve ya cerrahi kastrasyonun da tedaviye eklenmesi gerekmektedir. Over supresyonu ve ablasyonu çalışmalarda aynı etkinlikte olduğu görülmüştür. ${ }^{[43]}$ Medikal supresyon sağlamak için GNRH inhibitörleri (goserelin gibi) kullanılmaktadır. Premenopozal kadınlarda tamoksifen ilk tercih endokrin tedavi olarak bilinir. Bu kanıtlar eski çalışmalara dayansa da güncelliğini korumaktadır. ${ }^{[4]}$

Küçük hücreli dışı akciğer kanser (KHDAK) alanında yapılan çalışmalarda hastalığın tedavisine yönelik kemoterapi ajanları kemik rezorpsiyonunu yavaşlatır ve iskelet sistemi ilişkili olayların sıklığını azaltır. ${ }^{[45]}$

EGFR (epidermal growth factor receptor) mutasyonuna yönelik ajanlarının kullanıma girmesiyle birlikte yapılan çalışmalarla EGFR sinyal yolağının kemik metastazlarının oluşumunda önemli yere sahip olduğu gösterilmiştir. ${ }^{[45]}$ Sistemik tedavide öncelikle mutasyon belirlenmesi için doku veya likid biyopsi analizleri yapılarak EGFR, ALK, ROS yolağını aktive edici mutasyonları olup olmadığı değerlendirilir. Tümör hücrelerinin profilerasyonunu artırması üzerinden kemik metastazlarının yayılımına neden olan bu yolağın aktivitesinin durdurulması KHDAK olup EGFR mutasyonu saptanan ve kemik metastazları bulunan hastalarda değerli bir tedavi seçeneğidir. Anti-EGFR ajanların RANKL üzerinden de osteoklast aktivitesini durdurduğu ve osteoblastik aktiviteyi artırdığı da artık bilinenler arasındadır. [46] Tam olarak mekanizması bilinmese de özellikle tedaviye iyi yanıt veren hastalarda osteoblastik reaksiyonun şiddetli olduğu, görüntülemelerde artmış aktiviteye bağlı olarak yanlışlıkla hastalık progresyonu olarak kabul edilebileceği de göz önünde bulundurulmalıdır. [47] EGFR aktive edici mutasyonu KHDAK olgularının \%15'inde görülmektedir. Asya popülasyonunda bu mutasyonunun \%22-62 oranında görüldüğü bilinmektedir. ${ }^{[48]}$ Akciğer kanserinin sistemik tedavisinde vazgeçilmez kemoterapötik ajan olan platinlerle tek başına EGFR tirozinkinaz inhibitörlerinin (TKi) karşılaştırıldığı 13 Faz III çalışmanın meta-analizi sonucunda TKi'lerinin progresyonsuz sağkalımı belirgin uzattığı saptandı HR 0,43, \%95 Cl 0,38-0,49).. ${ }^{[49]}$ Erlotinib ve gefitinib birinci, afatinib ikinci jenerasyon ilaçlardır. Ekson 19 delesyon ve 21 mutasyon saptandığı zaman kullanılabilen erlotinib ve gefitinibe ek olarak, afatinib S768I, L861Q, ve G719X mutasyonlarında da kullanılabilir. Afatinib, erlotinib ve gefitinibe göre daha potent ajan olsa da yan etki profili de daha ciddidir. Anti-EGFR TKi'leriyle tedavi progresyona kadar devam edilmelidir. Tedavi sırasında direnç gelişen hastalarda 
T790M mutasyon analizi istenmeli ve pozitif saptandığı durumlarda Osimertinib tedavisine geçiş yapılmalıdır. Osimertinib birinci ve ikinci kuşak TKi’lerine direnç gelişen T790M mutasyonu saptanan olgularda pemetrekset/platin bazlı kemoterapiyle kıyaslandığı Faz III çalışmada progresyonsuz sağkalım (10,1 aya karşı 4,4 ay; HR 0,30, \%95 Cl 0,23-0,41) ve objektif yanıtta belirgin başarı göstermiştir. (\%71'e \%31; OR 5,4, \%95 Cl 3,47-9,48). ${ }^{[50]}$

ALK (anaplastik lenfoma kinaz) mutasyonu saptanan durumlarda bu yolak üzerinden etki eden TKi'leri crizotinib, alektinib, ceritinib, brigatinible tedavi verilebilir. Alk mutasyonu KHDAK olguların \%5'inde görülebilir. Sıralı tedavi tercih edilmekle birlikte alektinib ve brigatinib daha potent ajanlar olması ve beyin kan bariyerini daha iyi geçmeleri nedeniyle bu gibi olgularda ilk tercih TKi olabilir. ${ }^{[51]}$ Crizotinib ve ceritinib ROS mutasyonu pozitif olan KHDAK hastalarında başarılı sonuçlar gösteren ilaçlardır. ALK/ROS yolağı tirozin kinaz inhibitörlerine direnç gelişen olgularda Lorlatinib tedavisine geçilebilir. Yapılan FAZ II çalışmada 1 ve daha fazla TKI kullanmış ve progresyon gelişmiş hastalarda $\% 47$ oranında genel yanıt görülmüştür. ${ }^{[52]}$ Mutasyonların saptanmadığı ve ya çoklu hat TKi sonrası progrese olan olgularda kombinasyon veya tek ajan olarak sitotoksik tedavi rejimleri kullanılsa da, kemoterapötik ajanların sonraki hatlarda etkinliği az ve yan etki profili ise çok olduğu unutulmamalıdır.

Kemik metastazları olan solid tümörlerde antirezorptif ajanlar bisfosfonatlar ve denosumabdır. Denosumab nükleer faktör kappa B ligandının reseptörününe karşı geliştirilmiş monoklonal antikordur. Osteoblast ile osteoklast arasında en önemli etkileşim yolu olan RANK-RANKL ilişkisini hedef alan bu ajan böylelikle osteoklast aktivasyonunu engelleyerek kemik rezorpsiyonunu önlemiş olur. Denosumab özellikle meme, akciğer ve prostat kanserinin kemik metastazlarına bağlı oluşabilecek iskelet ilişkili olayları azaltmakta etkili bir ilaçtır.

Prostat kanseri hastalarında denosumab ve plasebonun karşılaştırıldığı bir çalışmada bilinen kemik metastazı olmayan ancak bu açıdan yüksek riskli olan hastalarda denosumab uygulanması kemik metastazı oluşum riskini belirgin azalttığı görülmüştür. (29,5 ve 25,2 ay, HR 0,85, \%95 Cl 0,73-0,98). . ${ }^{[33]}$

Denosumabın bir bisfosfonat olan zoledronik asitle karşılaştırıldığı üç büyük FAZ III çalışmanın sonuçları denosumabın zoledronik asite göre ilk iskelet ilişkili olay riskini azalttığını, bu olaya ve malign hiperkalsemiye kadar geçen süreyi artırdığı gösterilmiştir (HR 0,83, \%95 Cl 0,76-0,90). Çalışmaların hiç birinde zoledronik asit ve denosumab ile genel sağkalım ve progresyonsuz sağkalım açısından yarar saptanmasa da iskelet ilişkili olayların azalması olguların hayat kalitesinde belirgin iyileşme sağlamıştır. ${ }^{[54-58]}$

Dört haftada bir $120 \mathrm{mg}$ subkutan olarak uygulama bu ilacın daha az sıklıkta kullanılabilmesi için yapılmış Faz II çalışmada tedavi arası uzun olan hastalarda tümör döngüsünü gösteren parametrelerde artmış olması nedeniyle daha uzun aralıklı dönemlerle kullanımı şu an için uygun görülmemektedir.

Yan etki profiline baktığımız zaman hem bisfosfonat hem denosumab hipokalsemi riski taşısa da denosumab daha potent bir ajan olması nedeniyle hipokalsemi görülme riski daha fazladır. Her iki ajanı uygularken böbrek fonksiyon testleri göz önünde bulundurulmaII, kreatinin klirensi $<30 \mathrm{~mL} / \mathrm{dk}$ olan hastalarda derin hipokalsemi riski nedeniyle, denosumab tedavisinde dikkatli olunmalıdır. ${ }^{[56]}$ Tedavi süresince hastaların D vitamin düzeyleri, serum kalsiyumu ve böbrek fonksiyon testleri monitörize edilmelidir. Antirezorptif tedavi uygulanan hastaların günlük $1000 \mathrm{mg}$ kalsiyum ve $800 i$ vitamin D3 almalarına dikkat edilmelidir.

İlaç ilişkili çene kemiği osteonekrozu hem bisfosfonatlar hem de denosumabla görülebilecek ciddi bir yan etkidir. Denosumabın açık etiketli çalışmasında çene osteonekrozu görülme riski tedavinin ilk yılında 1,1 ikinci yılında 3,7 ve sonraki her yıl için 4,6 olarak görülmüştür. ${ }^{[59]} \mathrm{Bu}$ komplikasyonun önlenmesi için tedavi başlamadan önce hastaların ağız ve diş sağlığının kontrol edilmesi ve gereken tedavi ve önlemlerin alınması tedavi sürecinde ağız içi invaziv işlemlerin yapılmaması konusunda hastaların bilgilendirilmesi gerekmektedir.

Kemik metastazlarının tedavisinde genel yaklaşım olarak oligo-metastaz ve yaygın metastaz ayrımı yapılmalı, her iki durumda altta var olan kanserin biyolojik seyri ve sistemik tedavi olanakları değerlendirilmelidir. Kırık riski, spinal kord basısı riski gibi morbidite söz konusu mutlaka göz önünde tutulmalıdır. Klinik seyir, ağrı azaltma ihtiyacı, var olan kanserin yaygınlı̆̆ı ve tedaviye duyarlı olup olmadığı multidisipliner olarak değerlendirilmeli ve tedavi kararları bu prensiplerle uygulanmalıdır.

\section{KAYNAKLAR}

1. Mundy GR. Metastasis to bone: causes, consequences and therapeutic opportunities. Nat Rev Cancer 2002;2(8):58493. Crossref

2. Coleman R. Management of bone metastases. Oncologist 2000;5(6):463-70. Crossref

3. Saad F, Lipton A, Cook R, Chen Y, Smith M, Coleman R. Pathologic fractures correlate with reduced survival in patients with malignant bone disease. Cancer 2007;110(8):1860-7. Crossref 
4. Hirsh V, Saad F, Lipton A, Cook RJ, Langer CJ, Smith MR, Brown JE, Coleman RE. Zoledronic acid and survival in patients with metastatic bone disease from lung cancer and elevated markers of osteoclast activity. J Thorac Oncol 2008;3(3):228-36. Crossref

5. Tsuya A, Kurata T, Tamura K, Fukuoka M. Skeletal metastases in non small cell lung cancer: a retrospective study. Lung Cancer 2007;57(2):229-32. Crossref

6. Delea $T$, Langer C, McKiernan J, Liss M, EdelsbergJ, Brandman J, Sung J, Raut M, Oster G. The cost of treatment of skeletal related events in patients with bone metastases from lung cancer. Oncology 2004;67(5-6):390-6. Crossref

7. Coleman RE. Metastatic bone disease: clinical features, pathophysiology and treatment strategies. Cancer Treat Rev 2001;27:165-76. Crossref

8. Charhon SA, Chapuy MC, Delvin EE, Valentin-Opran A, Edouard $\mathrm{CM}$, Meunier PJ. Histomorphometric analysis of sclerotic bone metastases from prostatic carcinoma special reference to osteomalacia. Cancer 1983;51(5):918-24. Crossref

9. Roudier MP, Morrissey C, True LD, Higano CS, Vessella RL, Ott SM. Histopathological assessment of prostate cancer bone osteoblastic metastases. J Urol 2008;180(3):1154-60. Crossref

10. Coleman RE. The role of bone markers in metastatic bone disease. Cancer Treat Rev 2006;32(Suppl 1):1-2. Crossref

11. Ara $T$, Declerck YA. Interleukin- 6 in bone metastasis and cancer progression. Eur J Cancer 2010;46(7):1223-31. Crossref

12. Roodman GD. Mechanisms of bone metastasis. N Engl J Med 2004;350(16):1655-64. Crossref

13. Saki N, Abroun S, Farshdousti Hagh M, Asgharei F. Neoplastic bone marrow niche: hematopoietic and mesenchymal stem cells. Cell J 2011;13(3):131-6. Erişim: https://www.ncbi.nlm. nih.gov/pmc/articles/PMC3584472/

14. Lipton A, Theriault RL, Hortobagyi GN, Simeone J, Knight RD, Mellars K, Reitsma DJ, Heffernan M, Seaman JJ. Pamidronate prevents skeletal complications and is effective palliative treatment in women with breast carcinoma and osteolytic bone metastases: long term follow-up of two randomized, placebocontrolled trials. Cancer 2000;88(5):1082-90. Crossref

15. Saad F, Gleason DM, Murray R, Tchekmedyian S, Venner P, Lacombe L, Chin JL, Vinholes JJ, Goas JA, Zheng M. Longterm efficacy of zoledronic acid for the prevention of skeletal complications in patients with metastatic hormone-refractory prostate cancer. J Natl Cancer Inst 2004;96(11):879-82. Crossref

16. Rosen LS, Gordon D, Tchekmedyian NS, Yanagihara R, Hirsh V, Krzakowski M, Pawlicki M, De Souza P, Zheng M, Urbanowitz G, Reitsma D, Seaman J. Long-term efficacy and safety of zoledronic acid in the treatment of skeletal metastases in patients with nonsmall cell lung carcinoma and other solid tumors: a randomized, phase III, double-blind, placebo-controlled trial. Cancer 2004;100(12):2613-21. Crossref

17. McPhee SJ, Papadakis MA, Rabow MW. Current medical diagnosis and treatment 2014, 53rd ed. New York: McGrawHill Medical; 2014.

18. Yang HL, Liu T, Wang XM, Xu Y, Deng SM. Diagnosis of bone metastases: a meta-analysis comparing 18FDG PET, CT, MRI and bone scintigraphy. Eur Radiol 2011;21(12):2604-17. Crossref

19. National Comprehensive Cancer Network (NCCN) Breast Cancer NCCN Practice Guidelines in Oncology. Fort Washington, PA: NCCN, 2014. Ver. 2. Erişim: https://www. nccn.org/professionals/physician_gls/recently_updated.aspx
20. Nakai T, Okuyama C, Kubota T, Yamada K, Ushijima Y, Taniike K, Suzuki T, Nishimura T. Pitfalls of FDG-PET for the diagnosis of osteoblastic bone metastases in patients with breast cancer. Eur J Nucl Med Mol Imaging 2005;32(11):1253-8. Crossref

21. Wu LM, Gu HY, Zheng J, Xu X, Lin LH, Deng X, Zhang W, $\mathrm{Xu}$ JR. Diagnostic value of whole-body magnetic resonance imaging for bone metastases: a systematic review and metaanalysis. J Magn Reson Imaging 2011;34(1):128-35. Crossref

22. Gravis G, Fizazi K, Joly F, Oudard S, Priou F, Esterni B, Latorzeff I, Delva R, Krakowski I, Laguerre B, Rolland F, Théodore C, Deplanque G, Ferrero JM, Pouessel D, Mourey L, Beuzeboc P, Zanetta S, Habibian M, Berdah JF, Dauba J, Baciuchka M, Platini C, Linassier C, Labourey JL, Machiels JP, Kouri CE, Ravaud A, Suc E, Eymard JC, Hasbini A, Bousquet G, Soulie M. Androgen-deprivation therapy alone or with docetaxel in non-castrate metastatic prostate cancer (GETUG-AFU 15): a randomised, open-label, phase 3 trial. Lancet Oncol 2013;14(2):149-58. Crossref

23. Klotz L, O'Callaghan CJ, Ding K, Dearnaley DP, Higano CS, Horwitz EM, Malone S, Goldenberg SL, Gospodarowicz MK, Crook JM. A phase III randomized trial comparing intermittent versus continuous androgen suppression for patients with PSA progression after radical therapy: NCIC CTGPR 7/SWOGJPR 7/ CTSU JPR 7/UK Intercontinental Trial CRUKE/01/013(abstract \#3). J Clin Oncol 2011;29:7(Suppl):3. Crossref

24. Davis ID, Martin AJ, Stockler MR, Begbie S, Chi KN, Chowdhury S, Coskinas X, Frydenberg M, Hague WE, Horvath LG, Joshua AM, Lawrence NJ, Marx G, McCaffrey J, McDermott R, McJannett M, North SA, Parnis F, Parulekar W, Pook DW, Reaume MN, Sandhu SK, Tan A, Tan TH, Thomson A, Tu E, Vera-Badillo F, Williams SG, Yip S, Zhang AY, Zielinski RR, Sweeney CJ; ENZAMET Trial Investigators and the Australian and New Zealand Urogenital and Prostate Cancer Trials Group. Enzalutamide with Standard First-Line Therapy in Metastatic Prostate Cancer. N Engl J Med 2019;381(2):121-31. Crossref

25. Armstrong AJ, Zelig Szmulewitz R, Petrylak DP, Villers A, Azad A, Alcaraz A, Alekseev BY, Iguchi T, Shore ND, Rosbrook B, Sugg J, Baron B, Chen LF, Stenzl A. Phase 3 study of androgen deprivation therapy (ADT) with enzalutamide (ENZA) or placebo (PBO) in metastatic hormone-sensitive prostate cancer (mHSPC): The ARCHES trial (abstract). J Clin Oncol 37, 2019(suppl 7S; abstr 687). Erişim: https://meetinglibrary. asco.org/record/170727/abstract

26. Chi KN, Agarwal N, Bjartell A, Chung BH, Pereira de Santana Gomes AJ, Given R, Juárez Soto Á, Merseburger AS, Özgüroğlu M, Uemura H, Ye D, Deprince K, Naini V, Li J, Cheng S, Yu MK, Zhang K, Larsen JS, McCarthy S, Chowdhury S; TITAN Investigators. Apalutamide for Metastatic, Castration-Sensitive Prostate Cancer. N Engl J Med 2019;381(1):13-24. Crossref

27. Fizazi K, Tran N, Fein L, Matsubara N, Antolin AR, Alekseev $B Y$, Özgüroğlu M, Ye D, Feyerabend S, Protheroe A, Porre PD, Kheoh T, Park YC, Todd MB, Chi KN. Abiraterone plus Prednisone in Metastatic, Castration-Sensitive Prostate Cancer. N Engl J Med 2017;377(4):352-60. Crossref

28. Sydes MR, Spears MR, Mason MD, Clarke NW, Dearnaley DP, de Bono JS, Attard G, Chowdhury S, Cross W, Gillessen S, Malik ZI, Jones R, Parker CC, Ritchie AWS, Russell JM, Millman R, Matheson D, Amos C, Gilson C, Birtle A, Brock S, Capaldi L, Chakraborti P, Choudhury A, Evans L, Ford D, Gale J, Gibbs S, Gilbert DC, Hughes R, McLaren D, Lester JF, Nikapota A, O'Sullivan J, Parikh O, Peedell C, Protheroe A, Rudman SM, Shaffer R, Sheehan D, Simms M, Srihari N, Strebel R, Sundar S, Tolan S, Tsang D, Varughese M, Wagstaff J, Parmar BMK, James ND; The STAMPEDE Investigators. Adding abiraterone or docetaxel to long-term hormone therapy for prostate cancer: directly randomised data from the STAMPEDE multi-arm, multi-stage platform protocol. Ann Oncol 2018;29(5):1235-48. Crossref 
29. Feyerabend S, Saad F, Li T, Ito T, Diels J, Sanden SV, Porre PD, Roiz J, Abogunrin S, Koufopoulou M, Fizazi K. Survival benefit, disease progression and quality-of-life outcomes of abiraterone acetate plus prednisone versus docetaxel in metastatic hormone-sensitive prostate cancer: A network meta-analysis. Eur J Cancer 2018;103:78-87. Crossref

30. Sweeney CJ, Chen YH, Carducci M, Liu G, Jarrard DF, Eisenberger M, Wong YN, Hahn N, Kohli M, Cooney MM, Dreicer R, Vogelzang NJ, Picus J, Shevrin D, Hussain M, Garcia JA, DiPaola RS. Chemohormonal Therapy in Metastatic Hormone-Sensitive Prostate Cancer. N Engl J Med 2015;373(8):737-46. Crossref

31. James ND, de Bono JS, Spears MR, Clarke NW, Mason MD, Dearnaley DP, Ritchie AWS, Amos CL, Gilson C, Jones RJ, Matheson D, Millman R, Attard G, Chowdhury S, Cross WR, Gillessen S, Parker CC, Russell JM, Berthold DR, Brawley C, Adab F, Aung S, Birtle AJ, Bowen J, Brock S, Chakraborti P, Ferguson C, Gale J, Gray E, Hingorani M, Hoskin PJ, Lester JF, Malik ZI, McKinna F, McPhail N, Money-Kyrle J, O'Sullivan J, Parikh O, Protheroe A, Robinson A, Srihari NN, Thomas C, Wagstaff J, Wylie J, Zarkar A, Parmar MKB, Sydes MR; STAMPEDE Investigators. Abiraterone for Prostate Cancer Not Previously Treated with Hormone Therapy. N Engl J Med 2017;377:338. Crossref

32. Finn RS, Martin M, Rugo HS, Jones S, Im SA, Gelmon K, Harbeck N, Lipatov ON, Walshe JM, Moulder S, Gauthier E, Lu DR, Randolph S, Diéras V, Slamon DJ. Palbociclib and Letrozole in Advanced Breast Cancer. N Engl J Med 2016;375(20):1925-36. Crossref

33. Hortobagyi GN, Stemmer SM, Burris HA, Yap YS, Sonke GS, Paluch-Shimon S, Campone M, Petrakova K, Blackwell KL, Winer EP, Janni W, Verma S, Conte $\mathrm{P}$, Arteaga $\mathrm{CL}$, Cameron DA, Mondal S, Su F, Miller M, Elmeliegy M, Germa C, O'Shaughnessy J. Updated results from MONALEESA-2, a phase III trial of first-line ribociclib plus letrozole versus placebo plus letrozole in hormone receptor-positive, HER2-negative advanced breast cancer. Ann Oncol 2018;29(7):1541-7. Crossref

34. Goetz MP, Toi M, Campone M, Sohn J, Paluch-Shimon S, Huober J, Park IH, Trédan O, Chen SC, Manso L, Freedman OC, Garnica Jaliffe G, Forrester T, Frenzel M, Barriga S, Smith IC, Bourayou N, Di Leo A. MONARCH 3: Abemaciclib As Initial Therapy for Advanced Breast Cancer. J Clin Oncol 2017;35(32):3638-46. Crossref

35. Howell A, Robertson JF, Abram P, et al. Comparison of fulvestrant versus tamoxifen for the treatment of advanced breast cancer in postmenopausal women previously untreated with endocrine therapy: a multinational, doubleblind, randomized trial. J Clin Oncol 2004;22(9):1605-13. Crossref

36. Robertson JF, Llombart-Cussac A, Rolski J, Feltl D, Dewar J, Macpherson E, Lindemann J, Ellis MJ. Activity of fulvestrant $500 \mathrm{mg}$ versus anastrozole $1 \mathrm{mg}$ as first-line treatment for advanced breast cancer: results from the FIRST study. J Clin Oncol 2009;27(27):4530-5. Crossref

37. Howell A, Pippen J, Elledge RM, Mauriac L, Vergote I, Jones SE, Come SE, Osborne CK, Robertson JFR. Fulvestrant versus anastrozole for the treatment of advanced breast carcinoma: a prospectively planned combined survival analysis of two multicenter trials. Cancer 2005;104(2):236-9. Crossref

38. Di Leo A, Jerusalem G, Petruzelka L, Torres R, Bondarenko IN, Khasanov R, Verhoeven D, Pedrini JL, Smirnova I, Lichinitser MR, Pendergrass K, Malorni L, Garnett S, Rukazenkov Y, Martin M. Final overall survival: fulvestrant $500 \mathrm{mg}$ vs 250 $\mathrm{mg}$ in the randomized CONFIRM trial. J Natl Cancer Inst 2014;106(1):djt337. Crossref
39. Sledge GW Jr, Toi M, Neven $P$, Sohn J, Inoue K, Pivot $X$, Burdaeva O, Okera M, Masuda N, Kaufman PA, Koh $\mathrm{H}$, Grischke EM, Frenzel M, Lin Y, Barriga S, Smith IC, Bourayou N, Llombart-Cussac A. MONARCH 2: Abemaciclib in Combination With Fulvestrant in Women With HR+/HER2- Advanced Breast Cancer Who Had Progressed While Receiving Endocrine Therapy. J Clin Oncol 2017;35(25):2875-84. Crossref

40. André F, Ciruelos E, Rubovszky G, Campone M, Loibl S, Rugo HS, Iwata H, Conte P, Mayer IA, Kaufman B, Yamashita T, Lu YS, Inoue K, Takahashi M, Pápai Z, Longin AS, Mills D, Wilke C, Hirawat S, Juric D. Alpelisib for PIK3CA-Mutated, Hormone Receptor-Positive Advanced Breast Cancer. N Engl J Med 2019;380(20):1929-40. Crossref

41. Baselga J, Campone M, Piccart M, Burris HA 3rd, Rugo HS, Sahmoud T, Noguchi S, Gnant M, Pritchard KI, Lebrun F, Beck JT, Ito Y, Yardley D, Deleu I, Perez A, Bachelot T, Vittori L, Xu Z, Mukhopadhyay P, Lebwohl D, Hortobagyi GN. Everolimus in postmenopausal hormone-receptor-positive advanced breast cancer. N Engl J Med 2012;366(6):520-9. Crossref

42. Mehta RS, Barlow WE, Albain KS, Vandenberg TA, Dakhil SR, Tirumali NR, Lew DL, Hayes DF, Gralow JR, Linden HM, Livingston RB, Hortobagyi GN. Overall Survival with Fulvestrant plus Anastrozole in Metastatic Breast Cancer. N Engl J Med 2019;380(13):1226-34. Crossref

43. Taylor CW, Green S, Dalton WS, Martino S, Rector D, Ingle JN, Robert NJ, Budd GT, Paradelo JC, Natale RB, Bearden JD, Mailliard JA, Osborne CK. Multicenter randomized clinical trial of goserelin versus surgical ovariectomy in premenopausal patients with receptor-positive metastatic breast cancer: an intergroup study. J Clin Oncol 1998;16(3):994-9. Crossref

44. Sunderland MC, Osborne CK. Tamoxifen in premenopausal patients with metastatic breast cancer: a review. J Clin Oncol 1991;9(7):1283-97. Crossref

45. Kolaczkowska M, Junik R, Rzymkowska M, Kramer L. The effect of chemotherapy on bone metabolism in patients with non-small cell lung cancer. Pneumonol Alergol Pol 1998;66(5-6):283-9.

46. Lu X, Wang Q, Hu G, Van Poznak C, Fleisher M, Reiss M, Massague J, Kang Y. ADAMTS1 and MMP1 proteolytically engage EGF-like ligands in an osteolytic signaling cascade for bone metastasis. Genes Dev 2009;23(16):1882-94. Crossref

47. Pluquet E, Cadranel J, Legendre A, Faller M, Souquet $P$, Zalcman G, Perol M, Fraboulet G, Oliveiro G, Fraipont FD, Quoix E, Lantuejoul S, Milleron B, Moro-Sibilot D. Osteoblastic reaction in non-small cell lung carcinoma and its association to epidermal growth factor receptor tyrosine kinase inhibitors response and prolonged survival. J Thorac Oncol 2010;5(4):491-6. Crossref

48. Shi Y, Au JS, Thongprasert S, Srinivasan S, Tsai CM, Khoa MT, Heeroma K, Itoh Y, Cornelio G, Yang PC. A prospective, molecular epidemiology study of EGFR mutations in Asian patients with advanced non-small-cell lung cancer of adenocarcinoma histology (PIONEER). J Thorac Oncol 2014;9(2):154-62. Crossref

49. Lee CK, Brown C, Gralla RJ, Hirsh V, Thongprasert S, Tsai CM, Tan EH, Ho JCM, Chu DT, Zaatar A, Sanchez JAO, Vu W, Au JSK, Inoue A, Lee SM, Gebski V, Yang JCH. Impact of EGFR inhibitor in non-small cell lung cancer on progressionfree and overall survival: a meta-analysis. J Natl Cancer Inst 2013;105(9):595-605. Crossref 
50. Gainor JF, Dardaei L, Yoda S, Friboulet L, Leshchiner I, Katayama R, Jack ID, Gadgeel S, Schultz K, Singh M, Chin E, Parks M, Lee D, DiCecca RH, Lockerman E, Huynh T, Logan J, Ritterhouse LL, Le LP, Muniappan A, Digumarthy S, Channick C, Keyes C, Getz G, Dias-Santagata D, Heist RS, Lennerz $J$, Sequist LV, Benes $\mathrm{CH}$, lafrate AJ, Mino-Kenudson $\mathrm{M}$, Engelman JA, Shaw AT. Molecular Mechanisms of Resistance to First- and Second-Generation ALK Inhibitors in ALKRearranged Lung Cancer. Cancer Discov 2016;6(10):111833. Crossref

51. Camidge DR, Kim HR, Ahn MJ, Yang JC, Han JY, Lee JS, Hochmair MJ, Li JY, Chang GC, Lee KH, Gridelli C, Delmonte A, Garcia Campelo R, Kim DW, Bearz A, Griesinger F, Morabito A, Felip E, Califano R, Ghosh S, Spira A, Gettinger SN, Tiseo M, Gupta N, Haney J, Kerstein D, Popat S. Brigatinib versus Crizotinib in ALK-Positive Non-Small-Cell Lung Cancer. N Engl J Med 2018;379(21):2027-39. Crossref

52. Shaw AT, Solomon BJ, Besse B, Bauer TM, Lin CC, Soo RA, Riely GJ, Ou SHI, Clancy JS, Li S, Abbattista A, Thurm $\mathrm{H}$, Satouchi M, Camidge DR, Kao S, Chiari R, Gadgeel SM, Felip E, Martini JF. ALK Resistance Mutations and Efficacy of Lorlatinib in Advanced Anaplastic Lymphoma Kinase-Positive Non-Small-Cell Lung Cancer. J Clin Oncol 2019;37(16):13709. Crossref

53. Smith MR, Saad F, Coleman R, Shore N, Fizazi K, Tombal B, Miller K, Sieber P, Karsh L, Damião R, Tammela TL, Egerdie B, Poppel HV, Chin J, Morote J, Veiga FG, Borkowski T, Ye Z, Kupic A, Dansey R, Goessl C. Denosumab and bonemetastasis-free survival in men with castration-resistant prostate cancer: results of a phase 3 , randomised, placebocontrolled trial. Lancet 2012;379(9810):39-46. Crossref

54. Fizazi K, Carducci M, Smith M, Damião R, Brown J, Karsh L, Milecki P, Shore N, Rader M, Wang H, Jiang Q, Tadros $S$, Dansey R, Goessl C. Denosumab versus zoledronic acid for treatment of bone metastases in men with castrationresistant prostate cancer: a randomised, double-blind study. Lancet 2011;377(9768):813-22. Crossref
55. Himelstein AL, Foster JC, Khatcheressian JL, Roberts JD, Seisler DK, Novotny PJ, Qin R, Go RS, Grubbs SS, O'Connor T, Velasco MR, Weckstein D, O'Mara A, Loprinzi CL, Shapiro CL. Effect of Longer-Interval vs Standard Dosing of Zoledronic Acid on Skeletal Events in Patients With Bone Metastases: A Randomized Clinical Trial. JAMA 2017;317(1):48. Crossref

56. Stopeck AT, Lipton A, Body JJ, Steger GG, Tonkin K, de Boer RH, Lichinitser M, Fujiwara Y, Yardley DA, Viniegra M, Fan M, Jiang Q, Dansey R, Jun S, Braun A. Denosumab compared with zoledronic acid for the treatment of bone metastases in patients with advanced breast cancer: a randomized, doubleblind study. J Clin Oncol 2010;28(35):5132-9. Crossref

57. Henry DH, Costa L, Goldwasser F, Hirsh V, Hungria V, Prausova J, Scagliotti GV, Sleeboom H, Spencer A, VadhanRaj S, von Moos R, Willenbacher W, Woll PJ, Wang J, Jiang $\mathrm{Q}$, Jun S, Dansey R, Yeh H. Randomized, double-blind study of denosumab versus zoledronic acid in the treatment of bone metastases in patients with advanced cancer (excluding breast and prostate cancer) or multiple myeloma. J Clin Oncol 2011;29(9):1125-32. Crossref

58. Lipton A, Fizazi K, Stopeck AT, Henry DH, Brown JE, Yardley DA, Richardson GE, Siena S, Maroto P, Clemens M, Bilynskyy B, Charu V, Beuzeboc P, Rader M, Viniegra M, Saad F, Ke C, Braun A, Jun S. Superiority of denosumab to zoledronic acid for prevention of skeletal-related events: a combined analysis of 3 pivotal, randomised, phase 3 trials. Eur J Cancer 2012;48(16):3082-92. Crossref

59. Stopeck AT, Warner DJ. Response to letter to the EditorsSafety of long-term denosumab therapy. Support Care Cancer 2017; 25(2):353-5. Crossref 